\title{
Practical application of intelligent micro prefabricated substation in the concentration areas of the city
}

\author{
Qi Jiang ${ }^{1, a}$, Bo Jiang ${ }^{2}$, Minzhe Ren ${ }^{2}$ and Yu Zhang ${ }^{1}$ \\ ${ }^{1}$ State Grid Shaanxi Electric Power Company Training Center, 710032 Shaan'Xi Xi'an, China \\ ${ }^{2}$ State Grid Xi'an Electric Power Company, 710032 Shaan'Xi Xi'an, China
}

\begin{abstract}
With the development of smart grid, the integration of electrical devices has become the main trend. The construction of smart substation will meet the need of the development of smart grid. The application of the intelligent devices enables the interaction of information in real time, and it achieves the automation of the substation system. This paper introduces the pertinent technologies and applications of the intelligent micro substation, and there analyzes the requirements of the key technologies. There will be a discussion of the reliability, economy and social benefit of the intelligent substation which is based on the improvement of the existing traditional substation system structure. In this paper, the advantages of smart micro substation in the application of urban concentrated area are proved.
\end{abstract}

Keywords: micro prefabricated substation; integration; intelligent devices; urban concentrated area.

\section{Introduction}

In the process of the construction of strong smart grid, to ensure the safe and stable operation of power grid, the grid requires its structure to match grid environment. And construction of power grid environment which caters to the ultra high voltage (UHV) grid and intelligent distribution network. It can make the future power grid expanded largely. The construction of the intelligent distribution network and the construction of the UHV grid is the trend of modern power grid in China. Every resident will use electricity optionally is the pursuit goal of national power grid [1]. However, in the process of achieving this goal, power grid construction and the construction of the transmission lines has variable impact on the local environment. In this paper, by studying the risk communication strategy which is used to coordinate grid environment social environment, and natural environment, we can make the greatest advantage.

Under the background of smart grid, the communication standard of IEC61850 is required, intelligent devices such as electronic transformer, intelligent switch, and etc., and network of secondary devices which through the layer as process unit, delimited alternation unit and station control unit. Then construction of digital substation can be achieved. Digital substation is the integration of information sharing and interoperability of intelligent devices, it can integrate the information collection, transmission, processing and output. And it will achieve the whole process of digital communication of modern substation. With advanced functions, integrated applications and

\footnotetext{
a Corresponding author : duanlaiyue@126.com
} 
interactive as the goal, on the basis of digital substation, the substation automation technology is updated to achieve the development of the substation intelligent grid.

Compared with traditional substation, intelligent substation has the advantages of reliability, high efficiency, clean, environmental protection, economic security and human computer interaction. And functions of digital information, online analysis and decision-making, visual operation monitoring, information sharing inside and outside the interactive standardization, network communication platform are achieved [1-3].

The development and innovation of new technology in micro substation and its main application are:

(1) Research on the material of the transformer, the application of new materials to achieve the purpose of high efficiency and energy saving.

(2) The development of new electronic transformer and digital electrical measurement system to minimize the error of the system.

(3) Integration technology and substation automation system in-depth research, which makes the system automation degree become higher, the space of substation occupies is smaller, and the structure is more compact.

(4) Due to the application of interaction network of information communication system, so that the dispatch center can observe the system power flow, fault, state operation, and improve the operation reliability of the equipment.

\section{Intelligent micro transformer substation technology}

\subsection{Digital measurement of electrical signal}

Photoelectric coupling or electronic transformers to collect the system electrical signals such as voltage and current, which achieve electrical isolation, reduce measurement error and increase the dynamic measurement range, so that the information interaction is integrated. The digital measurement system is composed of a new type of voltage or current converter and a digital signal processing unit. For digital measurement system, one method is based on the capacitance or resistance voltage converter, the miniature current transformer and the Rogowski coil. The other method is using photoelectric voltage and current converter as the basic unit. The application of the new devices makes the whole structure of the measurement system more compact, and it requires less space which is more powerful to resist the electromagnetic interference [4-5].

\subsection{System integration automation}

Land prices in urban areas are much more expensive than that in general, and the space is limited. The large volume discrete structure of traditional substation violates the principle of urban rational planning, it occupies more land and it will affect road traffic. Therefore, in densely populated areas, systems need to be integrated to make rational distribution of resources. 


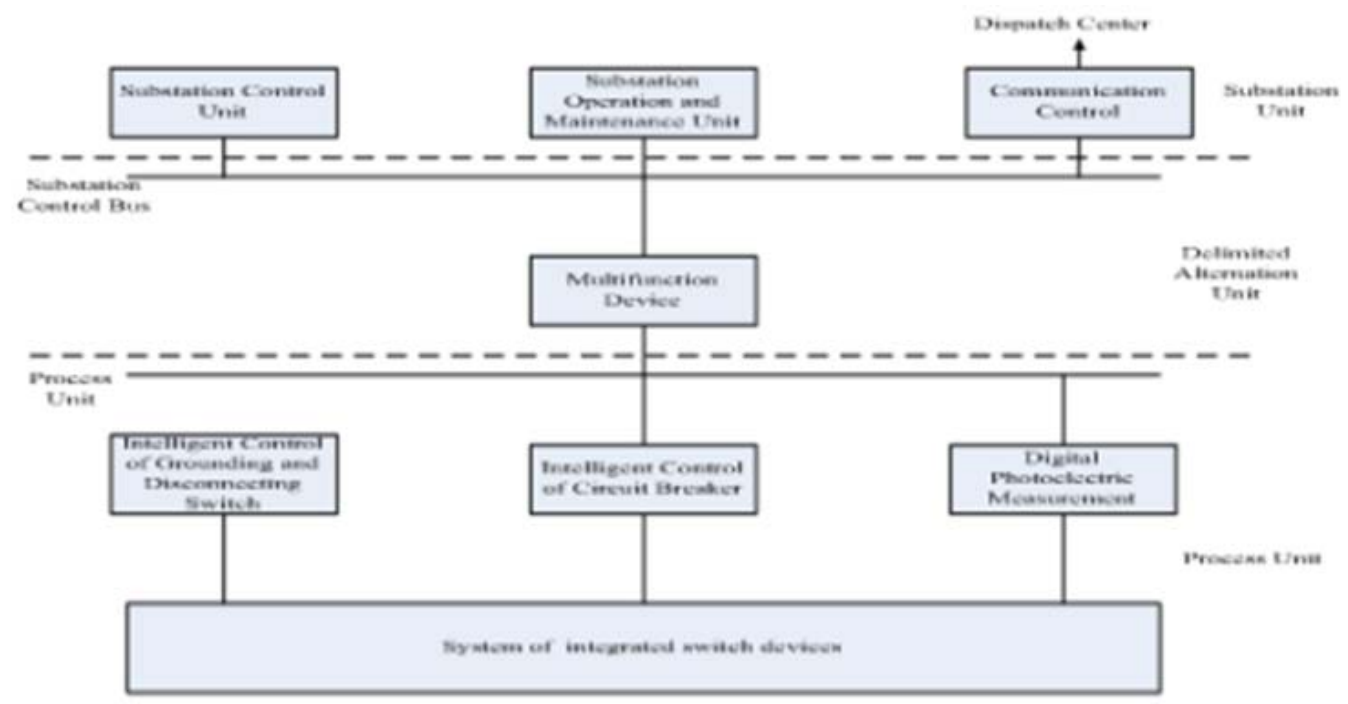

Figure 1. Fully integrated automation system

\subsubsection{Switch equipment integrated system}

The insulation sealed case is integrated with circuit breakers, disconnecting switches, grounding switches, bus bars, and the voltage or the current transformers. The micro transformer substation structure is more compact, and it is convenient to maintenance. Using the power electronic devices and microcomputer control monitoring devices to control the breaker to substitute the conventional controller, it is greatly reduce the operating energy.

\subsubsection{System information automation}

The micro intelligent substation realizes the information integration of distributing system, reduces the cost of the investment and realizes the information sharing. It reduces the delay of monitoring and controlling. The application of intelligent relay protection devices makes the fault cut out more accurately and more rapidly, and it improves the reliability of system, so that the equipment maintenance is more simple and more economical. 


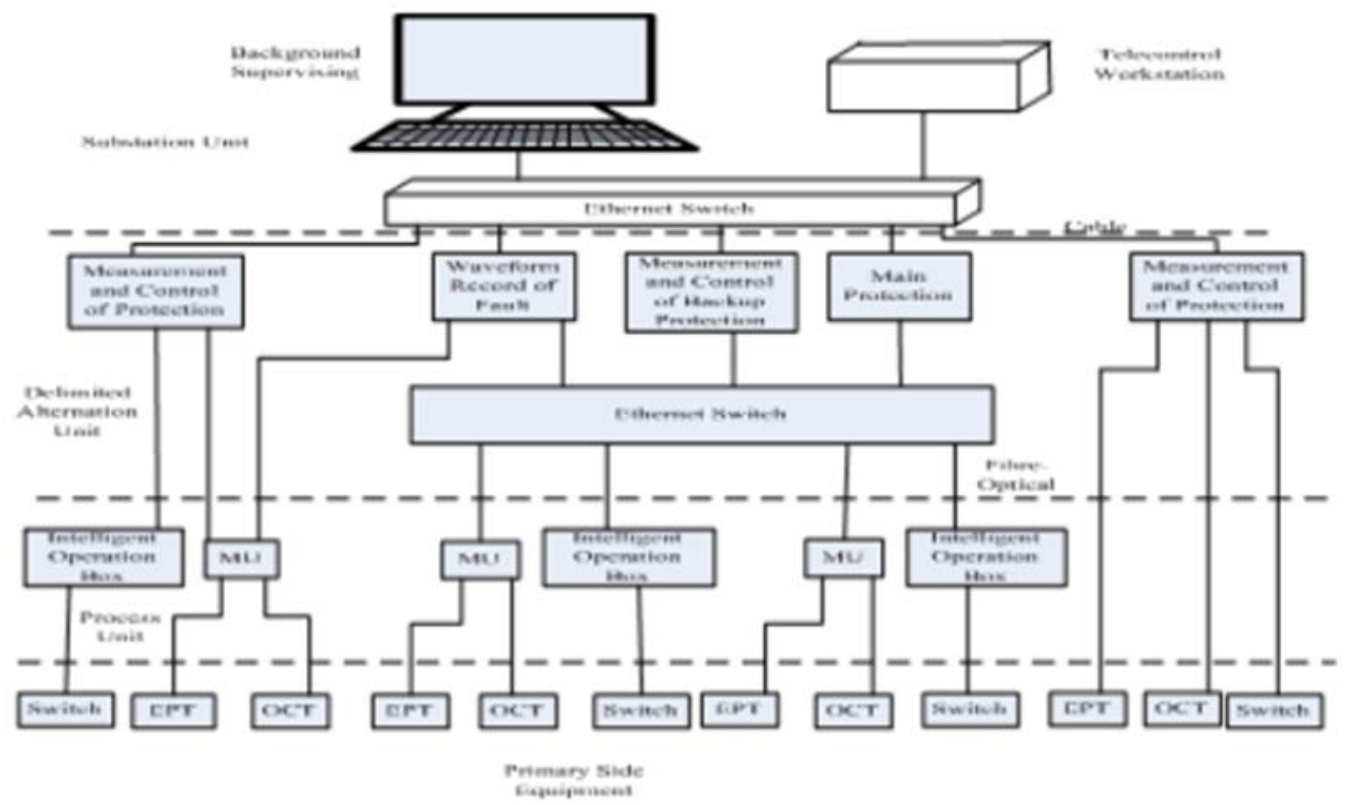

Figure 2. Structure diagram of digital substation system

In the diagram, where EPT is electric potential transformer, ECT is electric current transformer, OCT is optical current transformer, MU is merging unit.

\section{Engineering realization and analysis}

Figure 3 shows the conventional substation, and figure 4 shows the intelligent miniature substation. Intelligent miniature substation using integrated switch devices and intelligent relay protection devices, and control protection devices are placed in the switch site, the main wiring forms use ring bus. In the $110 \mathrm{kV}$ substation, the life cycle cost of IED equipment installation scheme and the standard $\mathrm{H}$ connection scheme is compared. And the timetable of construction with IED type intelligent components and conventional components such as transformers, circuit breakers is also compared. 


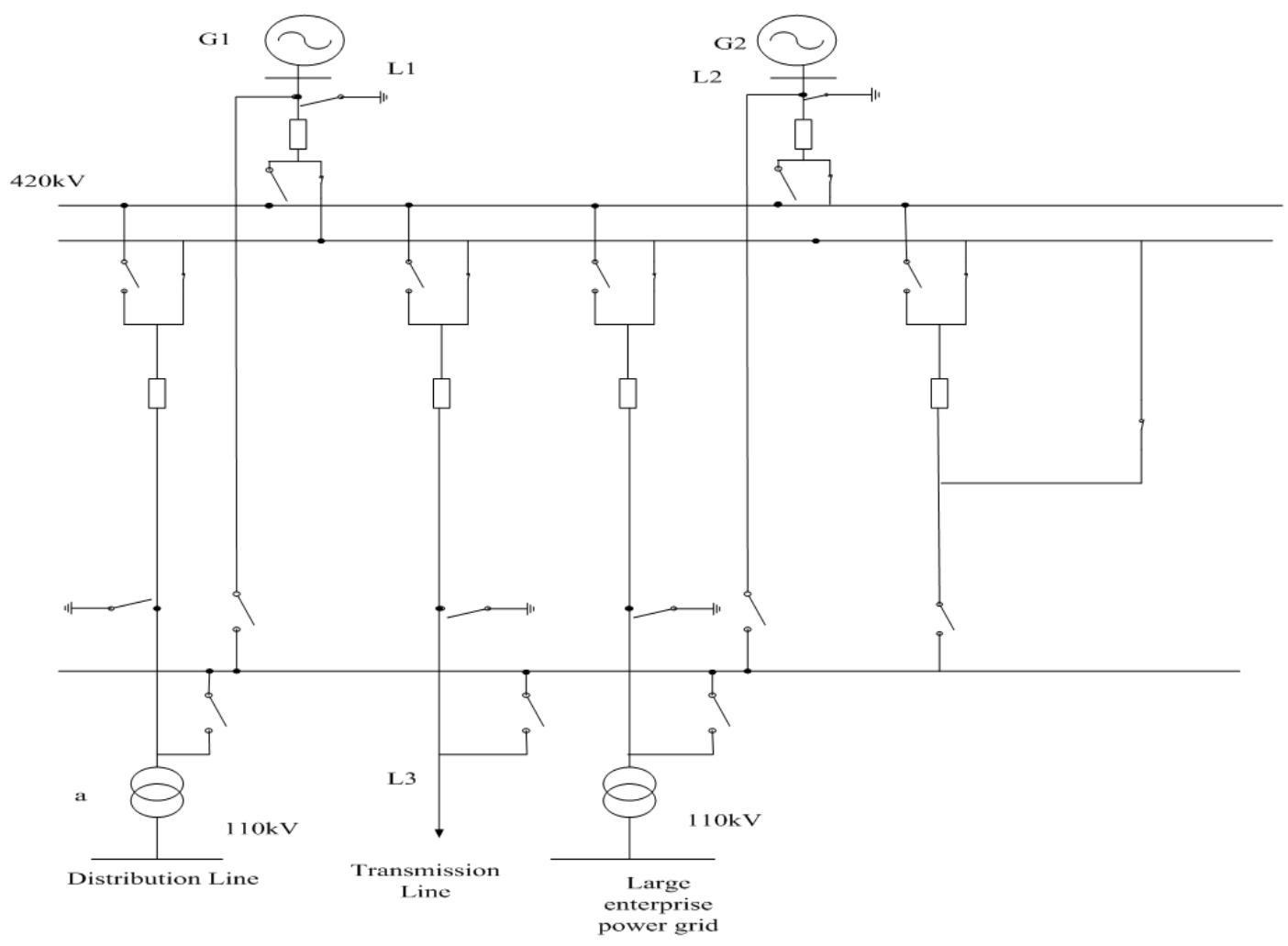

Figure 3. Diagram of a conventional substation

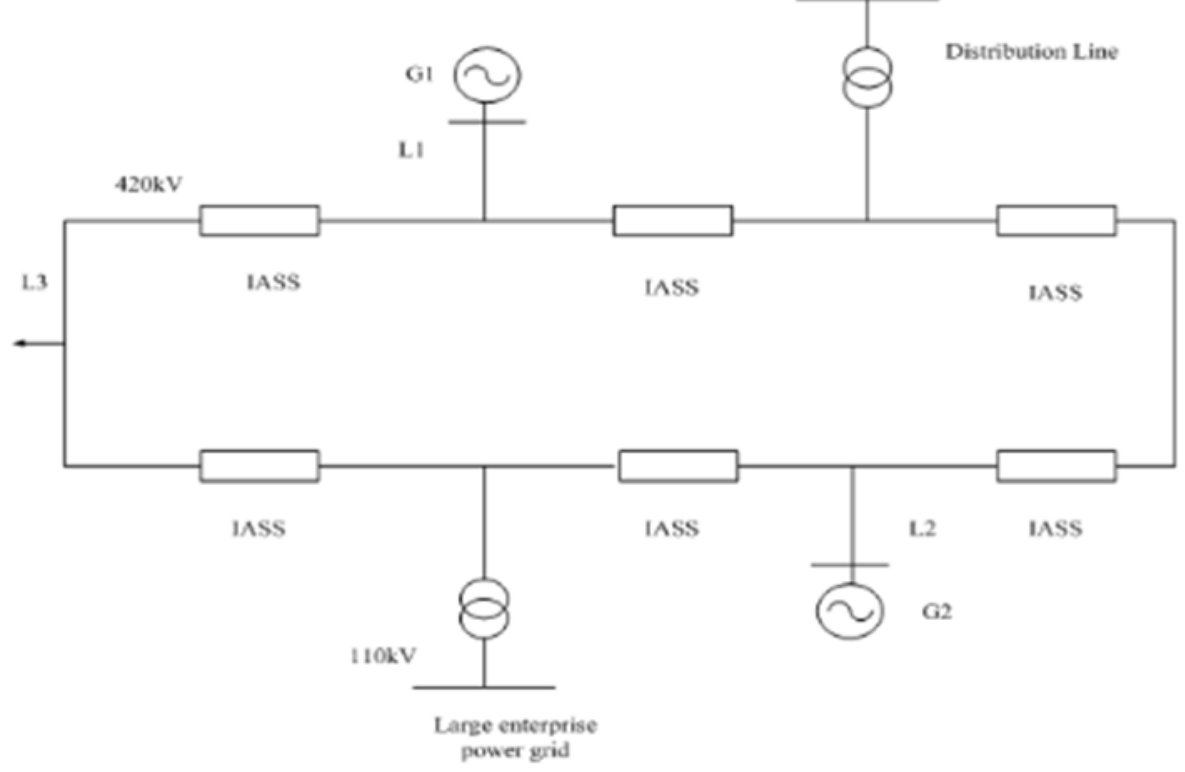

Figure 4. Diagram of a compact substation

In the figure, where IASS is integrated assembly switchgear system. 
The cost of life cycle cost (LCC) is the primary investment cost, which includes the fixed cost of devices, installation, site selection, construction, operation, maintenance and reliability.

$$
L C C=F C+O C+M C+L C
$$

Where FC is fixed primary cost, OC is operation cost, MC is maintenance cost, LC is outage cost. Reference [1] shows the equipment data.

Table 1. Comparison result of LCC

\begin{tabular}{|c|c|c|}
\hline Cost & Conventional substation & intelligent miniature substation \\
\hline IC & $100 \%$ & $78 \%$ \\
\hline MC & $0.75 \%$ & $0.38 \%$ \\
\hline FC & $18 \%$ & $2 \%$ \\
\hline LCC & $118.75 \%$ & $80.38 \%$ \\
\hline
\end{tabular}

Supposing there are 2 sets of on-line monitoring equipment in the transformer unit, results are as follow:

Table 2.

\begin{tabular}{|l|c|c|c|}
\hline Device type & $\begin{array}{l}\text { Time consuming of } \\
\text { conventional devices (h) }\end{array}$ & $\begin{array}{l}\text { Time consuming } \\
\text { of IED devices (h) }\end{array}$ & Time saving (h) \\
\hline $\begin{array}{l}\text { Monitoring devices } \\
\text { of the transformer } \\
\text { top oil temperature }\end{array}$ & 2 & 1 & 1 \\
\hline $\begin{array}{l}\text { Partial discharge } \\
\text { monitoring }\end{array}$ & 5 & 3 & 2 \\
\hline Total & 7 & 4 & 3 \\
\hline
\end{tabular}

If using 100MVA transformer, the electric price is set to 0.39 yuan $/ \mathrm{kWh}$, power generation cost is set to 0.25 yuan $/ \mathrm{kWh}$, the installation of intelligent devices can reduce the loss of power generation profit: $(0.39-0.25) * 100 * 1000 * 3=42000$ (yuan)

Supposing there are 2 sets of monitoring equipment in circuit breaker unit, results are as follow:

Table 3.

\begin{tabular}{|l|c|c|c|}
\hline Device type & $\begin{array}{l}\text { Time consuming of } \\
\text { conventional devices (h) }\end{array}$ & $\begin{array}{c}\text { Time consuming } \\
\text { of IED devices (h) }\end{array}$ & Time saving (h) \\
\hline $\begin{array}{l}S F_{6} \text { micro water } \\
\text { density monitoring }\end{array}$ & 3 & 2 & 1 \\
\hline $\begin{array}{l}\text { Partial discharge } \\
\text { monitoring }\end{array}$ & 5 & 3 & 2 \\
\hline Total & 8 & 5 & 3 \\
\hline
\end{tabular}

If the $110 \mathrm{kV}$ circuit breaker is used, the average load current is set to $230 \mathrm{~A}$, the installation of intelligent devices can reduce the loss of power generation profit:

$$
(0.39-0.25) * 110 * 230 * 1.732 * 3=18404.23 \text { (yuan) }
$$


Table 4. Economic comparison between traditional and intelligent substations

\begin{tabular}{|l|l|l|l|}
\hline & & \multicolumn{1}{|c|}{ conventional } & \multicolumn{1}{|c|}{ intelligent } \\
\hline \multirow{2}{*}{$\begin{array}{l}\text { Effect on the } \\
\text { environment }\end{array}$} & area covered & $100 \%$ & $34 \%$ \\
\cline { 2 - 4 } & Visualization degree & High & Middle or small \\
\hline \multirow{3}{*}{ Effect on the economy } & Primary devices & $100 \%$ & $120 \%$ \\
\cline { 2 - 4 } & Secondary devices & $100 \%$ & $95 \%$ \\
\cline { 2 - 4 } & LCC (20years) & $100 \%$ & Less than 65\% \\
\hline
\end{tabular}

According to the calculation results, it is known that the use of intelligent electronic equipment greatly reduces the installation time of equipment, reduces the power outage time, and enhances the reliability of power supply system.

\section{Conclusion}

Intelligent miniature substation which is based on smart grid theory in a densely populated area with digital integrated device instead of traditional substation large dispersion type equipment operation, it reduces the frequency of devices to exit, and improves the work efficiency of the device. The application of automatic monitoring and control system which reduces the failure rate of equipment, and guarantees the safety and efficiency of power system. The application of intelligent miniature substation in the urban can improve the utilization of resources, save the land resources, enhance the living conditions of citizen and strengthen the power network. The usage of micro intelligent substation will cut down the comprehensive cost and ensure the comfort experience of electric using of residents and industrial users.

\section{References}

1. QY Zeng, GL Li, Power System Technology, 26, 08(2002)

2. X Gao, PC Zhang, Power System Technology, 30, 23(2006)

3. WS Chen, HD Tang, East China Electric Power, 37, 5(2009)

4. GY Wang, L Su, Modern Electronics Technique, 21, (2009)

5. QR Liu, RT Liu, XJ Shang, RELAY, 35, 6(2007) 